\title{
Don't be too strict with yourself! Rigid negative self-representation in healthy subjects mimics the neurocognitive profile of depression for autobiographical
} memory

\section{Marco Sperduti ${ }^{1,2}$ *, Pénélope Martinelli ${ }^{1,2}$, Sandrine Kalenzaga ${ }^{1,2}$, Anne-Dominique Devauchelle ${ }^{3}$, Stéphanie Lion ${ }^{3}$, Caroline Malherbe ${ }^{3}$, Thierry Gallarda ${ }^{2,4}$, Isabelle Amado ${ }^{2,4}$, Marie-Odile Krebs ${ }^{2,4}$, Catherine Oppenheim ${ }^{3}$ and Pascale Piolino ${ }^{1,2,5}$}

${ }^{1}$ Laboratoire Mémoire et Cognition, Institut de Psychologie, Université Paris Descartes, Boulogne-Billancourt, France

2 INSERM U894, Centre de Psychiatrie et Neurosciences, Université Paris Descartes, Paris, France

${ }^{3}$ INSERM U894, Service d'Imagerie, Université Paris Descartes Sorbonne Paris Cité, Paris, France

${ }^{4}$ Faculté de Médecine, Centre Hospitalier Sainte-Anne, Service Hospitalier Universitaire, Université Paris Descartes, Paris, France

${ }^{5}$ Institut Universitaire de France, Paris, France

Edited by:

Hans J. Markowitsch, University of

Bielefeld, Germany

Reviewed by:

Seth Davin Norrholm, Emory

University, USA

Esther Fujiwara, University of Alberta,

Canada

*Correspondence.

Marco Sperduti, UMR S894,

Laboratoire Mémoire et Cognition,

Centre de Psychiatrie et

Neurosciences, Université Paris

Descartes, 2 ter rue d'Alesia, 75014

Paris, France.

e-mail: marcosperduti@yahoo.it
Autobiographical memory (AM) comprises representation of both specific (episodic) and generic (semantic) personal information. Depression is characterized by a shift from episodic to semantic AM retrieval. According to theoretical models, this process ("overgeneralization"), would be linked to reduced executive resources. Moreover, "overgeneral" memories, accompanied by a negativity bias in depression, lead to a pervasive negative self-representation. As executive functions and AM specificity are also closely intricate among "non-clinical" populations, "overgeneral" memories could result in depressive emotional responses. Consequently, our hypothesis was that the neurocognitive profile of healthy subjects showing a rigid negative self-image would mimic that of patients. Executive functions and self-image were measured and brain activity was recorded, by means of fMRI, during episodic AMs retrieval in young healthy subjects. The results show an inverse correlation, that is, a more rigid and negative self-image produces lower performances in both executive and specific memories. Moreover, higher negative self-image is associated with decreased activity in the left ventro-lateral prefrontal and in the anterior cingulate cortex, repeatedly shown to exhibit altered functioning in depression. Activity in these regions, on the contrary, positively correlates with executive and memory performances, in line with their role in executive functions and AM retrieval. These findings suggest that rigid negative self-image could represent a marker or a vulnerability trait of depression by being linked to reduced executive function efficiency and episodic AM decline. These results are encouraging for psychotherapeutic approaches aimed at cognitive flexibility in depression and other psychiatric disorders.

Keywords: autobiographical memory, depression, executive functions, self, neuroimaging, anterior cingulate cortex ventro-lateral prefrontal cortex

\section{INTRODUCTION}

Autobiographical memory (AM) is the "long term" memory system involved in the retention and retrieval of personal past events. A distinction between episodic AM (EAM) and semantic AM (SAM) has been proposed by several authors (Conway and Pleydell-Pearce, 2000; Conway, 2001; Tulving, 2002; Piolino et al., 2009; Klein and Gangi, 2010). The former refers to memory for unique events situated in time and space and recollected with phenomenological details and a sense of remembering, whereas the latter concerns decontextualized extended or repeated events and self-knowledge such as the name of one's acquaintances.

Autobiographical memory is impaired in a number of psychiatric disorders including post-traumatic stress disorder (McNally et al., 1994), schizophrenia (Riutort et al., 2003; Harrison and Fowler, 2004; Iqbal et al., 2004), and depression (Brittlebank et al., 1993; Kuyken and Dalgleish, 1995; Brewin et al., 1999; Wessel et al., 2001; Watson et al., 2013). The common pattern of AM impairment in these pathological states is characterized by a specific EAM deficit: patients recalling preferentially "overgeneral" memories (i.e., repeated and extended events) rather than unique episodes with a precise spatio-temporal context.

In depression the "overgenerality" characterizing AM retrieval is accompanied by a particular difficulty in recollecting details, even in the context of specific event retrieval (Lemogne et al., 2006). Interestingly, this lack of specificity has predictive value for the course of depression (Brittlebank et al., 1993; Peeters et al., 
2002; Raes et al., 2006; Hermans et al., 2008). Moreover, there is a large body of evidence showing that "overgeneral" AM is not simply a symptom of depression but can be regarded as a trait marker or vulnerability factor for this disease (Williams et al., 2007). Indeed, even in "non-clinical" populations, reduced memory specificity predicts increased emotional reactivity to stressful events (Mackinger et al., 2000; Gibbs and Rude, 2004; Van Minnen et al., 2005; Bryant et al., 2007; for a review, see Raes et al., 2007).

According to the Self-Memory System model (SMS, Conway and Pleydell-Pearce, 2000; Conway, 2005), specific memories are generally accessed through a hierarchical search starting from general events. This process engages executive functions in order to select relevant information and concurrently inhibit competing information. This theoretical model has been supported by numerous studies reporting that the ability to retrieve specific memories is linked to executive processes such as cognitive flexibility, inhibition, updating, shifting, and working memory (Baddeley and Wilson, 1986; Winthorpe and Rabbitt, 1988; Fivush and Nelson, 2004; Matuszewski et al., 2006; Piolino et al., 2007a,b, 2010; Addis et al., 2008; Raes et al., 2010; Ros et al., 2010; Coste et al., 2011).

Thus, "overgeneral" memories may arise when insufficient executive resources cause the premature break of the memory search at higher hierarchical levels. For instance, reduced AM specificity has been shown to be associated with poor performance in verbal fluency in controls (Williams and Dritschel, 1992) and in participants with eating disorders (Dalgleish et al., 2007). In the same vein, Heeren et al. (2009) have reported a parallel improvement of verbal fluency and AM specificity following a mindfulness training. Verbal fluency is sometimes considered as a measure of cognitive flexibility (Heeren et al., 2009), and more generally as a broad measure of executive control (Rosen and Engle, 1997).

Depressed patients show deficits in several executive functions including inhibition (Linville, 1996; MacQueen et al., 2000; Markela-Lerenc et al., 2006; Gohier et al., 2009) and cognitive flexibility (Naismith et al., 2003; Airaksinen et al., 2004; Meiran et al., 2010). Flexibility difficulties have emerged to be among the most prominent cognitive impairment in depression (Austin et al., 2001). Consequently, executive deficits are a central feature of a number of theoretical models of the depressive pathology (Hasher and Zacks, 1979; Ellis and Ashbrook, 1988; Hertel and Rude, 1991; Barrett et al., 2004). Thus, based on Conway and Pleydell-Pearce's (2000) proposition, the Capture and Rumination, Functional Avoidance, and eXecutive control model (CaRFAX model, Williams et al., 2007) proposes that "overgeneralization" in depression may result from executive impairment, that leads to difficulty in inhibiting inappropriate (i.e., "overgeneral") memories. Recently, however, Watson et al. (2013) did not find any relationship between verbal fluency and memory specificity in depressed patients.

Nevertheless, contrasting results have been reported concerning the role of executive deficit in depression, with some studies reporting a normalization of performance after recovery from recurrent depression (Beblo et al., 1999; Neu et al., 2001), whereas others reported a persistent impairment after remission (Beats et al., 1996; Reischies and Neu, 2000). Biringer et al. (2005) have shown no significant difference between recovered patients and controls on a composite score measuring global executive functioning, although, in the same group, semantic fluency performance was still below that of the controls. Such results could depend on the particular process tested, it has been proposed that executive deficits may be a risk factor for emotional disorders (Nolen-Hoeksema and Watkins, 2011), particularly for depression (Ingram et al., 2008).

Theoretical considerations (James, 1890; Conway and PleydellPearce, 2000; Gardiner, 2001), as well as behavioral ones (Rogers et al., 1977; Symons and Johnson, 1997) along with neuroimaging findings (Fletcher et al., 1996; Konishi et al., 2000; McDermott et al., 2000; Donaldson et al., 2001; Northoff and Bernpohl, 2004; Henson et al., 2005; Buckner et al., 2008; Sajonz et al., 2010; for reviews, see Cavanna and Trimble, 2006; Legrand and Ruby, 2009) suggest that AM and self-referential processing are intrinsically related. The relationship between self-concept and AM has been illustrated by a recent neuroimaging study reporting a correlation between the degree of certainty in self-evaluation and activity in dorso-medial prefrontal cortex (MPFC) (D'Argembeau et al., 2012). The authors proposed that this correlation may reflect the engagement of processes involved in the retrieval, integration, and evaluation of self-related information allowing the construction of a coherent self-image.

Thus, the categorical nature of "overgeneral" memories may contribute to other forms of "overgeneral" thinking found in depressed patients such as global negative self-judgment and "overgeneralization" in self-evaluation. Indeed, recurrent retrieval of "overgeneral" memories leads to categorical self-descriptors ("I am always boring") resulting in a retrieval style closely linked to rumination (Watkins and Teasdale, 2001; Raes et al., 2006; Debeer et al., 2011). Thus, depressed patients' cognition is characterized by negative schemas and a self-focus generating and maintaining a depressed mood and a pessimistic view of the self, the world, and the future (Beck, 1976, 2008; Beck et al., 1979). This negative bias has been associated with executive control impairments (Lo and Allen, 2011; De Lissnyder et al., in press), such as difficulties in inhibiting the processing of negative information (Joormann, 2004; Goeleven et al., 2006; see Gotlib and Joormann, 2010 for review). Such cognitive biases, in particular recurrent negative self-evaluations, are known to be predictive of future depressive symptoms (Carver, 1988; Dent and Teasdale, 1988). Accordingly, Mongrain (1990) demonstrated that high rates of dysfunctional attitudes, characterized by rigid content regarding self-worth leading to poor self-esteem (Mirabel-Sarron et al., 2001), are predictive of subsequent depressive symptoms (Beck, 1967; Beck et al., 1979; Segal and Ingram, 1994).

Cognitive theories posit that information processing and memory retrieval style may constitute a risk factor for the occurrence of depressive episodes. Thus, cognitive dysfunction may be an endophenotype for depression (Hasler et al., 2004). In particular, negative self-schemas (Ingram and Siegle, 2002) and self-evaluations (Carver, 1988; Dent and Teasdale, 1988) as well as rigid attitudes regarding self-judgment (Beck, 1967; Beck et al., 1979; Segal and Ingram, 1994) are known to represent vulnerability factors for depression.

Thus, we hypothesize that a rigid negative self-image in a "nonclinical" population would mimic the neurocognitive profile of 
depressed patients. To test our hypothesis, we assessed the subjective self-representation of 20 healthy subjects using a standard evaluation. Moreover, we measured different executive functions with standard neuropsychological tests. Then we asked participants to recall specific AMs while recording their brain activity by means of fMRI.

According to the existing literature (Joiner, 2000; Hammen, 2005; O'Brien et al., 2006; Evraire and Dozois, 2011; Morley and Moran, 2011; for review, see Sowislo and Orth, 2012), we expected to find that subjects showing higher negative self-image should show decreased scores on executive functions and, in turn, in the specificity of AMs. Regarding neuroimaging data, we expected to replicate previous findings on AM retrieval reporting activities in a widespread network encompassing fronto-parietal areas, cortical midline regions, and medial temporal structures (for a recent meta-analysis see Martinelli et al., 2012). Moreover, we predicted a significant correlation between the extent of the crystallized negative self-image and the activity in regions frequently reported as dysfunctional in depression (Brody et al., 1999; Mayberg et al., 1999; Drevets and Price, 2005; Murrough et al., 2011), in particular in lateral prefrontal cortex and anterior cingulate cortex (ACC) which are also linked to executive functions and memory retrieval (Ochsner et al., 2004; Kringelbach and Rolls, 2004; Ochsner and Gross, 2005; Niendam et al., 2012).

\section{MATERIALS AND METHODS PARTICIPANTS}

Twenty healthy young volunteers (25-44 years old, mean $=29.2 \pm$ $5.55,10$ women) all right-handed (according to the Edinburgh Handedness Inventory; Oldfield, 1971) and native French speakers participated to the study. All participants gave their informed written consent as required by the local ethic committee (CPP Ile de France $3 n^{\circ} 2687$ ). Exclusion criteria included presence of history of alcohol or substance abuse, head trauma, major diseases affecting brain functions, neuropsychiatric disorders such as clinical depression (tested with the Mini-International Neuropsychiatric Interview, Sheehan et al., 1998). Moreover, all participants were under the cutoff score on the French version of the Beck Depression Inventory (BDI-21, Beck et al., 1988; Bouvard and Cottraux, 1996, cutoff score $>14$; mean $=2.65 \pm 2.53$ ).

\section{SELF-CONCEPT ASSESSMENT}

Each subject fulfilled the Tennessee Self-Concept Scale (TSCS, Fitts and Warren, 1996: French version Duval et al., 2007). This scale assesses the multidimensionality of the self over six domains (family, personal, social, moral, physical, academic), and contains 82 descriptive statements (e.g., "I am an honest person") that have to be rated on a five-point scale (always false, mostly false, partly false/partly true, mostly true, always true) according to how well they match the participant's personality. Two standard scores were computed: (1) the degree of certainty (TSCS-C) (for a comparable method, see Addis and Tippett, 2004; Naylor and Clare, 2008) was measured through the amount of responses rated " 1 " (always false) or "5" (always true) and reflects "the degree of certainty about the way one sees oneself, thus reflecting the extent to which a definite sense of identity is expressed" (Naylor and Clare, 2008, p. 595). A more definite sense of self has been shown to reflect a less nuanced and a more crystallized and rigid self-concept (Klein and Gangi, 2010; Martinelli et al., 2013; Picard et al., in press); (2) the total score of the TSCS (TSCS-V) that reflects the global valence of the self (i.e., direction of the self, Addis and Tippett, 2004) and adds up the separate TSCS scores of identity, satisfaction, and behavior. High scores indicate a positive self-concept and higher self-esteem. Finally, a "negative crystallization score" (NCS) was computed by dividing the degree of certainty by the total score (each score being previously transformed into $z$ score), so the higher the NCS score the more the self-concept was crystallized and negative.

\section{NEUROPSYCHOLOGICAL MEASURES}

In order to characterize executive and working memory functions, we administered to the participants the following standard tests: the running span (Morris and Jones, 1990; Quinette et al., 2003; total score), the Stroop test (Stroop, 1935; interference score), and trail making test (Reitan, 1958, TMT B-A) to assess updating, inhibition, and shifting functions respectively (Miyake et al., 2000); verbal fluencies (Cardebat et al., 1990, sum of animal and letter $\mathrm{P}$ fluency), and digit and visuo-spatial spans (sum of backward and forward spans, Wechsler, 2000) to assess cognitive control and working memory functions. All scores were scaled in the same direction, so that higher scores reflect better performance.

\section{NEUROIMAGING PROCEDURE Pre-scanning interview}

In the pre-scanning interview, exclusion and inclusion criteria were verified by means of a clinical examination and psychometric tests. Then the TSCS and neuropsychological tests were administered to participants. In addition, subjects completed the Taste and Interest Questionnaire (TIQ) that was employed to create personal cues to trigger AM retrieval in the scanning session. The aim of this questionnaire was to collect information in order to create personalized cues for each participant without directly asking for descriptions of past memories to avoid re-encoding memories (Viard et al., 2010; Addis et al., 2011). Participants were informed that the purpose of the questionnaire was to obtain a description of their personality based on information about their main life interests. They had no prior knowledge of the aim of the fMRI task, preventing the possibility for participants of searching for memories linked to their taste and interests between the two sessions. The questionnaire concerned their personal lives from their birth to 5 years ago. It consists of a list of 220 interests including leisure, food, drink, transport, places where they lived, holidays, jobs, studies. For each item, the participants had to answer whether it was personally pertinent or not, rated by 1 and 0 respectively. When an item was pertinent, they had to rate how important (from 0 to 10) and frequent (Frequent/Rare) the activity or interest had been in their life. An activity or interest was used as a cue for episodic AM retrieval if it was pertinent, important ( $>5$ ), and rare. Twenty-four cues were created for each subject. Examples of activity assessed in the TIQ and the procedure to create cues is illustrated in the Table A1 in Appendix.

\section{Episodic autobiographical memory task}

The participants were first invited to take part in a training session before the fMRI scanning. Participants received detailed 
explanations on the nature of the task and participated in a brief simulation of the experiment on a laptop. They were instructed to recall EAMs elicited by the cues and to press a button when a memory was recalled. EAMs were defined as memories of a single event that occurred at a specific time and place, of short duration, lasting less than $24 \mathrm{~h}$. Participants were instructed to mentally relive personal episodes prompted by cues and to recollect affective and perceptual details (such as time, location, perceptions, feelings, scenery, and people present in the scene) (e.g.: "a unique memory linked to a trip in Italy"). After instructions, participants were trained on three trials with the experimenter providing feedback concerning the pertinence of the responses. The cues used for training were different from those used during the scanning session.

\section{Scanning session}

During fMRI recording, cues were visually presented in white font on a black background projected on a screen viewed by means of a mirror incorporated into the head-coil. E-Prime software (Psychology Software Tools, Inc., Pittsburgh, PA, USA) in combination with an Integrated Functional Imaging System (IFIS) was used for the presentation and timing of stimuli and collection of responses. Responses were made on an MR-compatible two-buttons box. Participants completed four functional scans in a single session. Each functional scan was composed of six items. Each trial lasted $26 \mathrm{~s}$ with the following time-course: the cue was presented for $5 \mathrm{~s}$, followed by a white cross at the center of the screen for $19 \mathrm{~s}$, then the cross turned red for $3 \mathrm{~s}$ informing the participants of the end of the present trial and the arrival of the next one. Participants were instructed to press a button as soon as they accessed a memory.

\section{Post scan interview}

Participants were asked to recall again each EAM retrieved in the scanner in order to check that memories met minimal criteria of specificity (single events, situated in time and place, lasting less than $24 \mathrm{~h}$, e.g., "the day of the visit of the exhibition 'The man on the moon' in the Palace of Tokyo museum in Paris, in August 2009"). The subsequent analyses were performed only on memories that met all the above mentioned criteria.

Episodic AMs were rated for specificity on standard scales (Levine et al., 2002; Piolino et al., 2009). More precisely, the presence of specific spatial and temporal details, and other contextual and phenomenological details in each evocation was noted (one point by type of detail, max. 4; e.g., "I remember my visit in the Palace of Tokyo as if I was still there, being together with Chiara in a room of the exhibition in the first floor in the dark to see the TV reports and talking with other visitors..., it was 6:00 p.m., after then we settled down in the restaurant of the outdoor museum in front of the Seine..."). We computed for each participant a global ratio of specificity (EPI score) totaling up the sum of spatiotemporal, other contextual and phenomenological details, divided by the number of EAM.

\section{fMRI METHOD}

\section{MRI data acquisition}

All data were acquired with a $3 \mathrm{~T}$ scanner (MR 750, General Electric Healthcare, Little Chalfont, UK). The anatomical scan used an inversion recovery 3-D T1-weighted gradientecho sequence images $(\mathrm{TE}=4.3 \mathrm{~ms}, \mathrm{TR}=11.2 \mathrm{~ms}, \mathrm{TI}=400 \mathrm{~ms}$, matrix $=384 \times 384$, slice thickness $=1.2 \mathrm{~mm}$ ). Functional images were acquired using a gradient-echo echoplanar (EPI) sequence $\left(\mathrm{TE}=30 \mathrm{~ms}, \mathrm{TR}=2000 \mathrm{~ms}\right.$, flip angle $=90^{\circ}$, matrix $=64 \times 64$, slice thickness $=3 \mathrm{~mm}, 42$ contiguous sections). The first four volumes of each functional run were discarded in order to allow longitudinal magnetization to approach equilibrium.

\section{Pre-processing of fMRI data}

All data were processed using SPM5 software (Statistical Parametric Mapping 5, Welcome Dept. Cognitive Neurology, UK; www.fil.ion.ucl.ac.uk/spm). Standard pre-processing procedures were applied to MRI data. EPI volumes were corrected for slice timing, realigned to the first image, co-registered with the highresolution $\mathrm{T}_{1}$-weighted image and normalized into the Montreal Neurological Institute (MNI) template. Finally, the normalized EPI volumes were smoothed using an isotropic Gaussian kernel filter of $5 \mathrm{~mm}$ full-width half-maximum.

\section{First level analysis of fMRI data}

Only correct trials were used for the subsequent analyses. A trial was considered as correct if (1) the participant had pressed the button during the trial (indicating retrieval) and (2) the description of the memory during the debriefing corresponded to EAM (see above). Memory retrieval (i.e., access or strategic research phase) was modeled by convolving the time period between cue presentation and subjects' response with the hemodynamic response function (HRF). For each subject, General Linear Model was used to estimate the parameters of interest. Parameters of movement were also included in the model as regressors of no interest. A whole brain $t$-test was computed to estimate the contrast of interest for each subject: EAM vs. rest. Then, contrasts for each individual were used for second-level analyses.

\section{Second-level analysis of fMRI data}

We computed a whole brain $t$-test using first level contrasts for each subject. An activation map resulting from this analysis was then used to mask subsequent correlation analysis. The rationale of this choice was that we were only interested in correlations in areas showing a significant activation. Threshold for the whole brain $t$-test was fixed at $p<0.01$ corrected for multiple comparison using the false discovery rate (FDR) with an extended threshold of $k=20$.

\section{Correlations}

We computed correlations between signal change in regions showing a significant activity at the group level and the NCS using the multiple regression model in SPM in which we entered contrast images as well as the NCS for each subject as a covariate. The threshold for this analysis was fixed at $p<0.01$ (uncorrected) with an extended threshold of $k=10$. Then we extracted percentage signal change of clusters showing a significant correlation using Marsbar toolbox (Brett et al., 2002) and calculated correlations between signal change and the executive and EAM scores outside SPM using STATISTICA7C. 


\section{RESULTS}

\section{BEHAVIORAL RESULTS}

Participants showed a high percentage of correct trials (CR, mean $87.85 \pm 7.70$ ) and a rapid response time (RT, mean $2.28 \pm 0.94 \mathrm{~s}$ ). NCS correlated negatively with inhibition, verbal fluency, and working memory performances. A trend for a negative correlation between NCS and the episodic score was found $(r=-0.44$, $p=0.054)$. Interestingly, the two basic scores of the TSCS, certainty (TSCS-C) and valence (TSCS-V) of self-concept, did not singularly correlate with executive functions and the episodic score. The episodic score correlated positively with performance on executive functions, namely inhibition, shifting (TMT B-A), verbal fluency, and working memory. For detailed results see Table 1.

\section{fMRI RESULTS}

\section{Activation during EAM retrieval}

We reported activations in several clusters encompassing lateral (mainly on the left side) and medial frontal regions and posterior medial regions. In particular we found activations in cortical midline structures comprising MPFC, ACC, posterior cingulate
(PCC), and precuneus. Moreover insula, cerebellum, inferior parietal, and occipital regions as well as lateral and medial temporal regions comprising the hippocampus were found (Figure 1). The list of local activation maxima is reported on Table 2 .

\section{Correlation between brain activations, neuropsychological, and EAM scores}

We observed negative correlations between the NCS and the dorsal ACC (dACC) and the ventro-lateral prefrontal cortex (vLPFC) in the left side (Figure 2). See Table 3 for peaks coordinates. A positive correlation was reported between verbal fluency and both regions, whereas only the dACC showed a significant correlation with inhibition performance. Moreover, for correlations between activity in these regions and the other scores of interest we found a positive correlation with episodic scores. The basic scores of the TSCS did not show significant correlations with the other variables. For detailed results see Table 4.

A series of partial correlations (Bravais-Pearson) were calculated between the NCS, the episodic score, and activity in the dACC and vLPFC, separately controlling for inhibition, fluency,

Table 1 | Correlations between self-concept, episodic and neuropsychological scores.

\begin{tabular}{|c|c|c|c|c|c|c|c|c|c|c|c|}
\hline & NCS & TSCS-C & TSCS-V & EPI & FLU & INHIB & TMT B-A & R-SPAN & WM & CR & RT \\
\hline NCS & & 0.040 & -0.365 & -0.438 & -0.626 & -0.582 & -0.271 & -0.203 & -0.449 & 0.149 & 0.011 \\
\hline$p$ & & 0.869 & 0.114 & 0.054 & 0.003 & 0.007 & 0.248 & 0.391 & 0.047 & 0.532 & 0.965 \\
\hline TSCS-C & 0.040 & & 0.748 & -0.118 & -0.227 & -0.051 & 0.120 & 0.114 & -0.058 & 0.086 & -0.321 \\
\hline$p$ & 0.869 & & 0.000 & 0.622 & 0.337 & 0.832 & 0.613 & 0.632 & 0.809 & 0.719 & 0.168 \\
\hline TSCS-V & -0.365 & 0.748 & & 0.040 & 0.207 & 0.194 & 0.202 & 0.369 & 0.346 & -0.020 & -0.094 \\
\hline$p$ & 0.114 & 0.000 & & 0.867 & 0.381 & 0.412 & 0.394 & 0.110 & 0.135 & 0.934 & 0.692 \\
\hline EPI & -0.438 & -0.118 & 0.040 & & 0.523 & 0.545 & 0.451 & 0.411 & 0.668 & 0.363 & 0.076 \\
\hline$p$ & 0.054 & 0.622 & 0.867 & & 0.018 & 0.013 & 0.046 & 0.072 & 0.001 & 0.115 & 0.750 \\
\hline FLU & -0.626 & -0.227 & 0.207 & 0.523 & & 0.478 & 0.536 & 0.492 & 0.596 & 0.264 & -0.008 \\
\hline$p$ & 0.003 & 0.337 & 0.381 & 0.018 & & 0.033 & 0.015 & 0.027 & 0.006 & 0.260 & 0.975 \\
\hline INHIB & -0.582 & -0.051 & 0.194 & 0.545 & 0.478 & & -0.275 & 0.498 & 0.581 & -0.074 & 0.088 \\
\hline$p$ & 0.007 & 0.832 & 0.412 & 0.013 & 0.033 & & 0.241 & 0.025 & 0.007 & 0.755 & 0.712 \\
\hline TMT B-A & -0.271 & 0.120 & 0.202 & 0.451 & 0.536 & -0.275 & & 0.429 & 0.417 & 0.460 & -0.209 \\
\hline$p$ & 0.248 & 0.613 & 0.394 & 0.046 & 0.015 & 0.241 & & 0.059 & 0.068 & 0.041 & 0.377 \\
\hline R-SPAN & -0.203 & 0.114 & 0.369 & 0.411 & 0.492 & 0.498 & 0.429 & & 0.689 & 0.100 & 0.174 \\
\hline$p$ & 0.391 & 0.632 & 0.110 & 0.072 & 0.027 & 0.025 & 0.059 & & 0.001 & 0.677 & 0.462 \\
\hline WM & -0.449 & -0.058 & 0.346 & 0.668 & 0.596 & 0.581 & 0.417 & 0.689 & & 0.134 & 0.435 \\
\hline$p$ & 0.047 & 0.809 & 0.135 & 0.001 & 0.006 & 0.007 & 0.068 & 0.001 & & 0.573 & 0.055 \\
\hline CR & 0.149 & 0.086 & -0.020 & 0.363 & 0.264 & -0.074 & 0.460 & 0.100 & 0.134 & & -0.189 \\
\hline$p$ & 0.532 & 0.719 & 0.934 & 0.115 & 0.260 & 0.755 & 0.041 & 0.677 & 0.573 & & 0.425 \\
\hline $\mathrm{RT}$ & 0.011 & -0.321 & -0.094 & 0.076 & -0.008 & 0.088 & -0.209 & 0.174 & 0.435 & -0.189 & \\
\hline$p$ & 0.965 & 0.168 & 0.692 & 0.750 & 0.975 & 0.712 & 0.377 & 0.462 & 0.055 & 0.425 & \\
\hline
\end{tabular}

NCS, negative crystallization score; TSCS-C, TSCS, certainty score; TSCS-V, TSCS, valence score; EPI, episodic Score of EAM; FLU, verbal fluency Score; INHIB, interference score Stroop, inhibition; TMTB-A, trail making test B-A score, shifting; R-SPAN, running span, updating; WM, working memory score, digit and visuo-spatial spans; $C R$, correct responses; RT, response time. Correlations written in bold font are significant $(p<0.05$ to $p<0.001)$. 


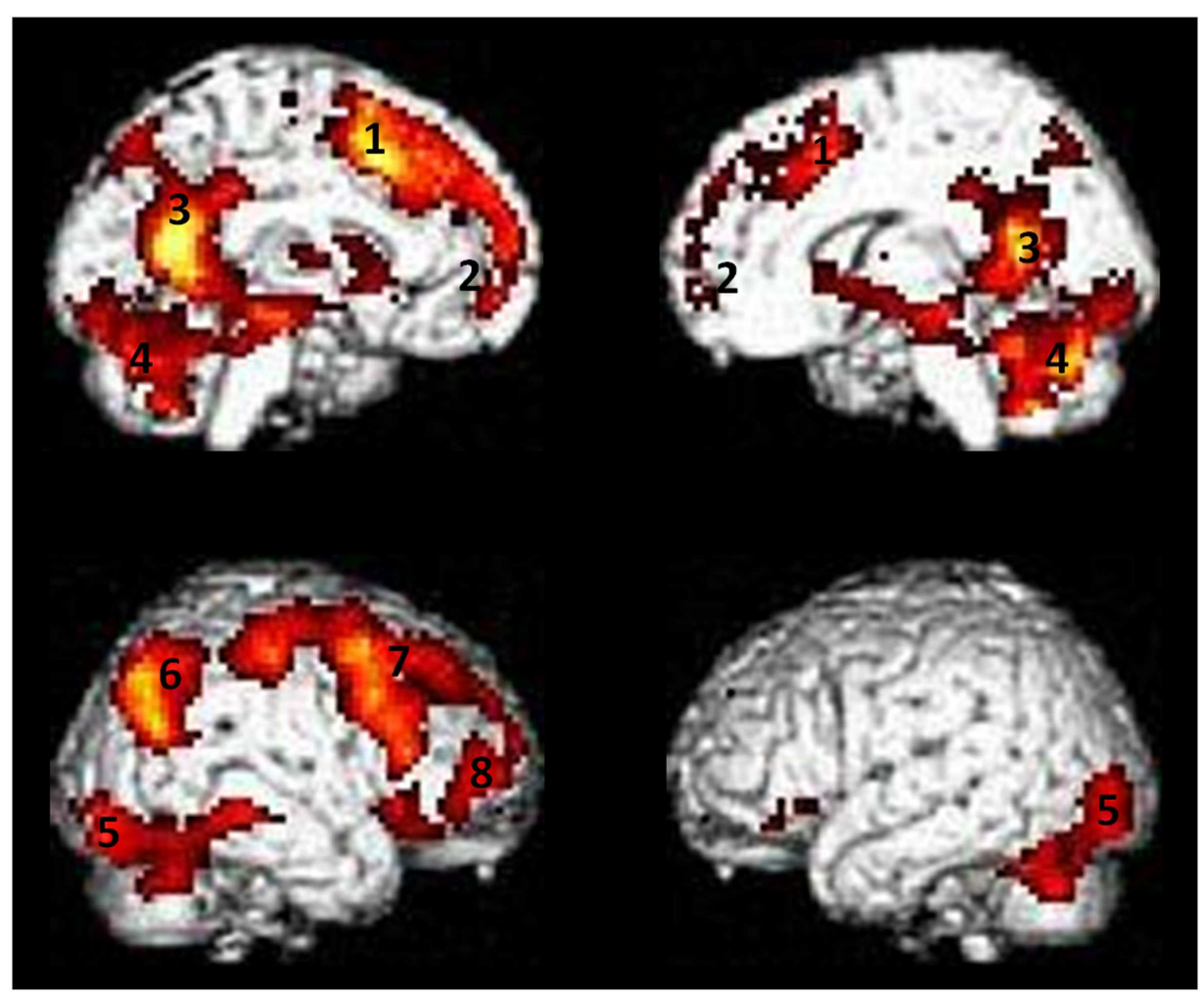

FIGURE 1 | Areas showing activity during retrieval of episodic autobiographical memory. (1) Dorsal anterior cingulate cortex (dACC), (2) medial prefrontal cortex (MPFC), (3) posterior cingulate cortex/precuneus (PCC/precuneus), (4) cerebellum, (5) occipital cortex, (6) posterior parietal cortex (PPC), (7) dorso-lateral prefrontal cortex (dLPFC), (8) ventro-lateral prefrontal cortex (vLPFC). Results are superimposed to a single subject rendering and are significant at a threshold of $p<0.01$ corrected for multiple comparison using the false discovery rate (FDR) with an extended threshold of $k=20$. and working memory scores. When controlling for inhibition, fluency, or working memory performance the correlation between NCS and the episodic score disappeared. Moreover, when controlling for the fluency score, the correlations between the NCS and the vLPFC, and between the episodic score and the same region become marginally significant. See Table 5 for detailed results.

\section{DISCUSSION}

In the present study we assessed, through standard tests, selfconcept, executive functions' profile as well as brain activations during an EAM retrieval task in a group of young healthy subjects. In line with our hypotheses we reported that participants with a rigid negative self-representation tend to retrieve less detailed memories and show poorer performance on executive scores, in particular on inhibition, verbal fluency, and working memory. Interestingly, the valence and the certainty of self-representation taken alone did not seem to be linked either with executive functions, or with EAM performance. This result suggests that a negative self-representation accompanied by a flexible cognitive style would not necessarily lead to "depressive-like" cognitive functioning, and that a rigid self schema would not be inadaptative if not centered on negative content (see Martinelli et al., 2012). Moreover, two regions that were activated in the access or strategic research phase of EAM retrieval, the dACC and the left vLPFC, showed a negative correlation with the NCS, a positive correlation with verbal fluency, and a positive correlation with the episodic scores. Finally, only activity in dACC correlated significantly with inhibition.

Our results are coherent with models of AM retrieval assigning a central role to executive functions in the hierarchical search of episodic details (Baddeley and Wilson, 1986; Conway and Fthenaki, 2000; Conway and Pleydell-Pearce, 2000). Moreover, the negative correlation between executive and the NCS scores is in agreement with previous proposals of executive dysfunction as a trait marker or risk factor for depression (Hasler et al., 2004). Overall, our results suggest that executive functions could have a central role in both inefficient search mechanisms during EAM retrieval and in the construction of a rigid or schematic self-representation, concerning, above all, negative content. Of particular interest is the fact that the marginally significant correlation we found between the NCS and episodic details was removed when controlling for executive functions. Thus, executive functions may mediate the relationship between the NCS and low episodic score. This is in line with the CaRFAX model that assigns a central role to executive deficits in reduced AM specificity in depression (Williams et al., 2007). Also, our neuroimaging results indicated that activity 
Table 2 | List of regions activated during memory retrieval.

\begin{tabular}{|c|c|c|c|c|c|c|}
\hline \multirow[t]{2}{*}{ Lobe } & \multirow[t]{2}{*}{ Labels } & \multirow[t]{2}{*}{ BA } & \multirow[t]{2}{*}{$t$} & \multicolumn{3}{|c|}{ MNI } \\
\hline & & & & $x$ & $y$ & $z$ \\
\hline \multirow[t]{15}{*}{ Frontal } & ACC & 32 & 13.91 & -6 & 15 & 45 \\
\hline & Mid. front. & 6 & 11.81 & -39 & 9 & 54 \\
\hline & Prec. gyr. & 4 & 8.36 & -36 & -27 & 54 \\
\hline & SMA & 6 & 8.04 & -6 & 18 & 63 \\
\hline & Mid. front. & 8 & 7.81 & -24 & 27 & 51 \\
\hline & vLPFC & 44 & 7.71 & -51 & 12 & 36 \\
\hline & dLPFC & 9 & 7.59 & -18 & 36 & 45 \\
\hline & VLPFC & 45 & 6.53 & -54 & 24 & 15 \\
\hline & dLPFC & 9 & 6.37 & -9 & 54 & 36 \\
\hline & VMPFC & 11 & 6.34 & -9 & 60 & -6 \\
\hline & Mid. front. & 10 & 6.26 & -33 & 48 & 12 \\
\hline & Mid. CC & 23 & 6.09 & 0 & -36 & 33 \\
\hline & Prec. gyr. & 6 & 5.98 & -33 & -18 & 63 \\
\hline & vLPFC & 47 & 5.59 & -36 & 45 & 3 \\
\hline & VLPFC & 47 & 4.61 & 30 & 27 & 0 \\
\hline \multirow[t]{7}{*}{ Parietal } & PCC & 23 & 12.28 & -6 & -57 & 18 \\
\hline & Pre. cun. & 7 & 11.53 & 6 & -57 & -48 \\
\hline & Inf. par. & 7 & 10.37 & -36 & -72 & 42 \\
\hline & Ang. gyr. & 39 & 9.98 & -48 & -69 & 30 \\
\hline & Inf. par. & 40 & 8.72 & -39 & -33 & 48 \\
\hline & Sup. par. & 7 & 7.54 & -30 & -69 & 51 \\
\hline & Postc. gyr. & 3 & 7.31 & -45 & -27 & 51 \\
\hline \multirow[t]{5}{*}{ Temporal } & Fus. gyr. & 37 & 10.3 & -27 & -36 & -18 \\
\hline & Fus. gyr. & 37 & 8.43 & 30 & -57 & -27 \\
\hline & Inf. temp. & 20 & 6.56 & -54 & -39 & -12 \\
\hline & Hipp. & & 5.54 & -21 & -18 & -15 \\
\hline & pHipp. & & 4.94 & 24 & -18 & -21 \\
\hline \multirow[t]{6}{*}{ Occipital } & Calcarine & 17 & 13.48 & -9 & -60 & 12 \\
\hline & Lingual gyr. & 17 & 12.18 & 12 & -54 & 9 \\
\hline & Calcarine & 18 & 8.55 & 9 & -72 & -30 \\
\hline & Inf. occ. & 19 & 8.01 & -39 & -87 & -6 \\
\hline & Inf. occ. & 18 & 6.29 & -30 & -90 & -6 \\
\hline & Inf. occ. & 19 & 6.21 & 39 & -75 & -18 \\
\hline \multirow[t]{2}{*}{ Other } & Cerebellum & & 6.65 & 0 & -66 & -30 \\
\hline & Insula & & 5.95 & -30 & 24 & -3 \\
\hline
\end{tabular}

$B A$, Brodmann area; $A C C$, anterior cingulate cortex; Mid. front., middle frontal gyrus; Prec. gyr., precentral gyrus; SMA, supplementary motor area; VLPFC, ventro-lateral prefrontal cortex; $d L P F C$, dorso-lateral prefrontal cortex; VMPFC, ventro-medial prefrontal cortex; Mid. CC, middle cingulate cortex; PCC, posterior cingulate cortex; Pre. cun., precuneus; Inf. par., inferior parietal gyrus; Ang. gyr., angular gyrus; Sup. par., superior parietal gyrus; Postc. gyr., postcentral gyrus; Fus. gyr., fusiform gyrus; Inf. temp., inferior temporal gyrus; Hipp., hippocampus; pHipp, parahippocampus; Lingual gyr., lingual gyrus; Inf. occ., inferior occipital gyrus.

in AACC and vLPFC that were engaged in EAM retrieval, negatively correlated with the NCS and, in turn, positively correlated with executive functions and episodic details, suggesting shared neurocognitive processes.
The ACC has been divided into a dorsal "cognitive" and a rostral "emotional" component (Bush et al., 1998; Whalen et al., 1998; Etkin et al., 2006). The dACC is commonly reported to be recruited during tasks eliciting cognitive control, conflict resolution, and error monitoring (Bush et al., 2000; Beckmann et al., 2009). It has been found to be activated, together with other fronto-parietal regions, across diverse executive functions such as flexibility, inhibition, shifting, and working memory (Hedden and Gabrieli, 2010; Niendam et al., 2012). Regarding inhibition specifically, the positive correlation we found between dACC activity and the interference score corroborates previous findings reporting specific activity in the dACC during Stroop tasks (Bush et al., 1998). Moreover, ACC activity elicited during a Stroop task has been shown to be lower after a negative mood induction (Nixon et al., 2012).

Thus, dACC can be seen as supporting superordinate cognitive control processes (Niendam et al., 2012). This is in line with its role in EAM retrieval and with the pattern of correlations reported in the present study. Indeed, as mentioned above, during memory search, executive functions are supposed to be recruited to select relevant information and concurrently inhibit competing information.

Moreover, in healthy subjects, the dACC is known to exert an inhibitory influence over the limbic system that is devoted to emotional processing (Bush et al., 2000; Shafritz et al., 2006). In individuals with depression, hypo-activation in dACC is assumed to disrupt this inhibitory control leading to the attentional bias for negative information (Greicius et al., 2007). Indeed, in a task requiring participants to disengage attention from negative irrelevant material, depressed patients showed increased activity of the dACC, suggesting a greater cognitive and neural resources requirement during controlled emotional processing (Foland-Ross et al., 2013). Thus, the lower activity of dACC in subjects with greater NCS scores and the concurrent positive correlation between its activity and the inhibition score seems to mimic the neural profile associated with impaired emotional control in depression. This assumption appears quite relevant considering that the Stroop task has been shown to activate the dACC in healthy controls but not in subjects with mood-disorders (George et al., 1997).

Convincing evidence suggests that lateral prefrontal cortex is involved in high-order control processes regulating cognition and behavior (Miller, 2000; Miller et al., 2002; Petrides, 2005). Within prefrontal cortex, a dorso-ventral functional specialization has been proposed. The dorso-lateral prefrontal cortex would be engaged in on-line monitoring and manipulation of information in working memory, whereas the VLPFC would underpin active selection, comparison, and judgment of information held in short and long term memory (Petrides, 1995, 2002, 2005). Concerning memory retrieval, the same author reported that vLPFC, corresponding to BA 45 and 47 , would be essential when active strategic retrieval of memories is at stake, but not during automatic retrieval. More recently, Badre and Wagner (2007) proposed a further subdivision of the vLPFC into the anterior vLPFC, corresponding to BA 47 , and the mid-vLPFC, composed by BA 45 . They reported evidence for a two-process account of controlled memory retrieval mechanisms implemented in the VLPFC with the anterior portion engaged in strategic processes and top down facilitation 


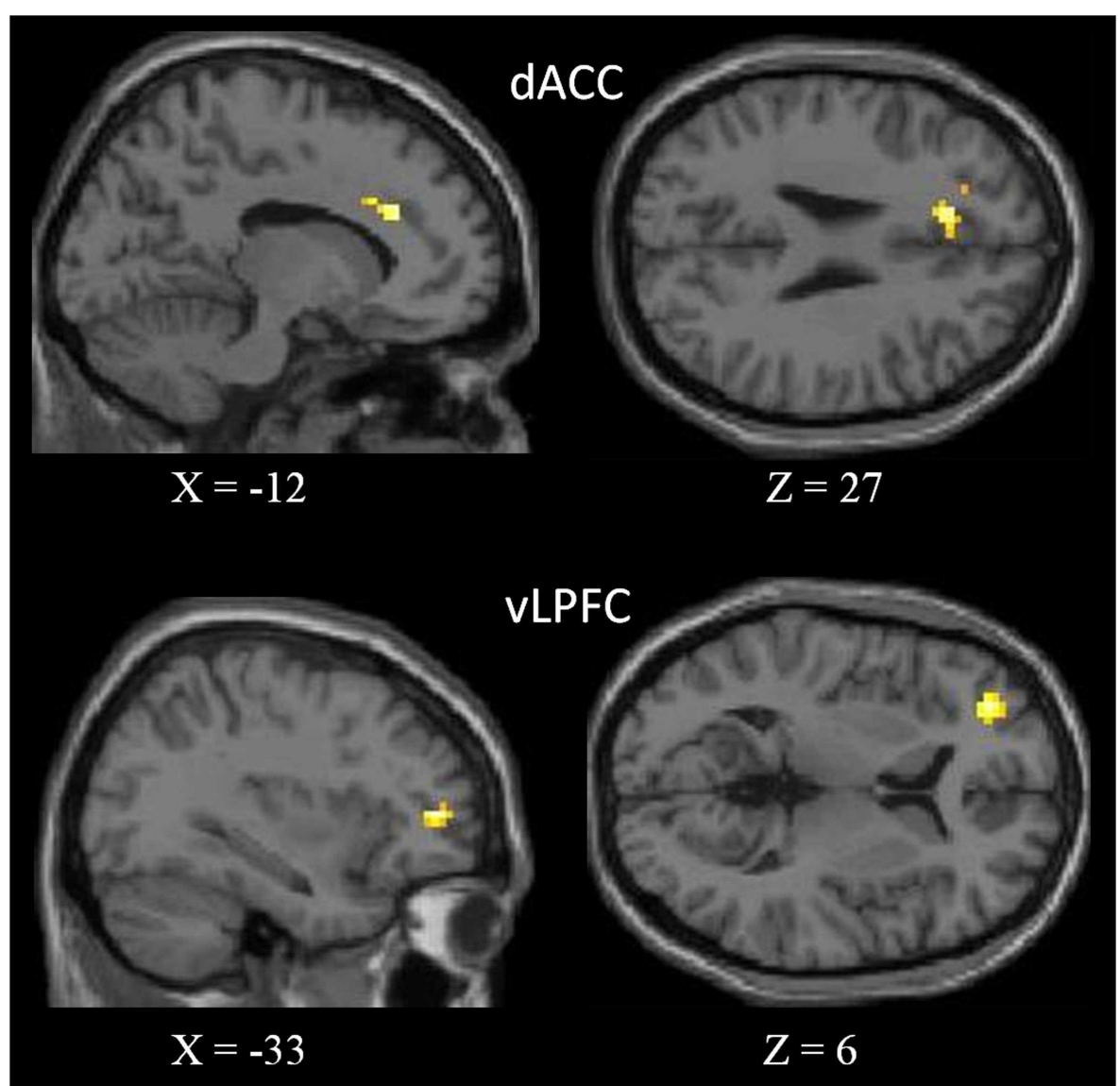

FIGURE 2 | Areas showing negative correlation with the NCS. In the upper part of figure, the dorsal anterior cingulate cortex (dACC), and in the bottom, the ventro-lateral prefrontal cortex (vLPFC). Results are superimposed to a single subject T1-weighted image normalized to the $\mathrm{MNI}$ stereotaxic space. Results are significant at a threshold of $p<0.01$ (uncorrected) with an extended threshold of $k=10$. of relevant information and the mid-vLPFC that would be especially in charge of post retrieval selection of relevant information between competing representations. This account of the anterior vLPFC involvement in effortful strategic memory retrieval fits well with its activation in our task and the correlation found with performance on verbal fluency tasks.

Besides its strategic role in memory retrieval, vLPFC is also known to modulate emotional responses of the amygdala through an attentional biasing mechanism (Wager et al., 2008). Moreover, vLPFC is frequently altered in depression at both the functional (Brody et al., 1999; Mayberg et al., 1999) and structural levels (mainly BA 47, Drevets and Price, 2005). These changes may participate in explaining the depression-related negative bias. Indeed, there is evidence of attenuated neural response in the vLPFC of depressed patients when responding to targets that were preceded by sad distracters (Wang et al., 2008; Dichter et al., 2009). Moreover, rumination on bad feelings and past experiences is maintained in depressed patients by an impaired cognitive control mechanism associated with the hypoactivation of the left prefrontal regions, in particular of the VLPFC (Ochsner et al., 2004; Ray et al., 2005; Gotlib and Hamilton, 2008).
Table 3 | List of regions showing a correlation with the CNS.

\begin{tabular}{llllllr}
\hline Lobe & Labels & BA & $\boldsymbol{t}$ & \multicolumn{3}{c}{ MNI } \\
\cline { 5 - 7 } & & & & $\boldsymbol{x}$ & $\boldsymbol{y}$ & $\boldsymbol{z}$ \\
\hline Frontal & VLPFC & 47 & 4.24 & -33 & 45 & 6 \\
& dACC & 32 & 3.76 & -12 & 27 & 27
\end{tabular}

$B A$, Brodmann area; $d A C C$, dorsal anterior cingulate cortex; $V L P F C$, ventro-lateral prefrontal cortex.

Based on the aforementioned literature on abnormalities in emotional processing in depression, Murrough et al. (2011) proposed a model suggesting that depression-related functional changes are characterized by an imbalance between the cognitive control, implemented in the PFC, and the emotional system, based on limbic structures. In other words, the under-activity of the former regions is thought to mediate executive impairment and to contribute to explaining the failure of cognitive control on emotion in depression.

Interestingly, Beevers et al. (2010) reported that patients with a mild to moderate depression experienced difficulty recruiting 
Table 4 | Correlations between brain activity self-concept, episodic and neuropsychological scores.

\begin{tabular}{lrrlllllll}
\hline & NCS & TSCS-C & TSCS-V & EPI & FLU & INHIB & TMT B-A & R-SPAN & WM \\
\hline$d A C C$ & $-\mathbf{0 . 7 1 7}$ & -0.001 & 0.153 & $\mathbf{0 . 6 3 0}$ & $\mathbf{0 . 5 0 4}$ & $\mathbf{0 . 5 8 7}$ & 0.285 & 0.114 & 0.330 \\
$p$ & $\mathbf{0 . 0 0 0}$ & 0.996 & 0.520 & $\mathbf{0 . 0 0 3}$ & $\mathbf{0 . 0 2 4}$ & $\mathbf{0 . 0 0 7}$ & 0.224 & 0.634 & 0.155 \\
vLPFC & $-\mathbf{0 . 6 3 2}$ & 0.156 & 0.233 & $\mathbf{0 . 5 9 1}$ & $\mathbf{0 . 5 3 8}$ & 0.311 & 0.332 & 0.127 \\
$p$ & $\mathbf{0 . 0 0 3}$ & 0.511 & 0.324 & $\mathbf{0 . 0 0 6}$ & $\mathbf{0 . 0 1 5}$ & 0.182 & 0.152 & 0.333 \\
& & & & & & & &
\end{tabular}

NCS, negative crystallization score; TSCS-C, TSCS, certainty score; TSCS-V, TSCS, valence score; EPI, episodic score of EAM; FLU, verbal fluency score; INHIB, inter ference score Stroop, inhibition; TMTB-A, trail making test B-A score, shifting; R-SPAN, running span, updating; WM, working memory score, digit and visuo-spatial spans; dACC, dorsal anterior cingulate cortex; vLPFC, ventro-lateral prefrontal cortex. Correlations written in bold font are significant ( $p<0.05$ to $p<0.001$ ).

Table 5 | Partial correlations between brain activity, self-concept, and episodic score, controlling for executive functions performances.

\begin{tabular}{|c|c|c|c|c|}
\hline & NCS & EPI & dACC & vLPFC \\
\hline \multicolumn{5}{|l|}{ INHIB } \\
\hline NCS & & -0.18 & -0.57 & -0.58 \\
\hline$p$ & & 0.469 & 0.011 & 0.009 \\
\hline EPI & -0.18 & & 0.46 & 0.53 \\
\hline$p$ & 0.469 & & 0.049 & 0.020 \\
\hline $\mathrm{dACC}$ & -0.57 & 0.46 & & 0.77 \\
\hline$p$ & 0.011 & 0.049 & & 0.000 \\
\hline vLPFC & -0.58 & 0.53 & 0.77 & \\
\hline$p$ & 0.009 & 0.020 & 0.000 & \\
\hline \multicolumn{5}{|l|}{ FLU } \\
\hline NCS & & -0.17 & -0.60 & -0.45 \\
\hline$p$ & & 0.499 & 0.007 & 0.053 \\
\hline EPI & -0.17 & & 0.50 & 0.43 \\
\hline$p$ & 0.499 & & 0.030 & 0.066 \\
\hline $\mathrm{dACC}$ & -0.60 & 0.50 & & 0.70 \\
\hline$p$ & 0.007 & 0.030 & & 0.001 \\
\hline VLPFC & -0.45 & 0.43 & 0.70 & \\
\hline$p$ & 0.053 & 0.066 & 0.001 & \\
\hline \multicolumn{5}{|l|}{ WM } \\
\hline NCS & & -0.21 & -0.67 & -0.57 \\
\hline$p$ & & 0.395 & 0.002 & 0.010 \\
\hline EPI & -0.21 & & 0.58 & 0.52 \\
\hline$p$ & 0.395 & & 0.009 & 0.021 \\
\hline $\mathrm{dACC}$ & -0.67 & 0.58 & & 0.75 \\
\hline$p$ & 0.002 & 0.009 & & 0.000 \\
\hline vLPFC & -0.57 & 0.52 & 0.75 & \\
\hline$p$ & 0.010 & 0.021 & 0.000 & \\
\hline
\end{tabular}

NCS, negative crystallization score; EPI, episodic score of EAM; INHIB, interference score Stroop, inhibition; FLU, verbal fluency score; WM, working memory score; $d A C C$, dorsal anterior cingulate cortex; $V L P F C$, ventro-lateral prefrontal cortex. Correlations written in bold font are significant $(p<0.05$ to $p<0.001)$.

regions involved in cognitive control, notably vLPFC, when processing emotional information, whereas activity of cerebral regions that typically subserve emotional experience per se, such as amygdala and orbital PFC, were not associated with depressive symptoms. The authors concluded that more severe forms of depression may be necessary before neural activity in these emotional processing regions would be attained (Siegle et al., 2007; Hamilton and Gotlib, 2008).

In summary, according to the aforementioned literature, we propose that the neurocognitive profile of people with a negative crystallized self-representation would mimic that of mildly to moderately depressed patients. In particular, the negative rigid self-representation might result from diminished executive functions resources that, in turn, could affect EAM. This cognitiveprofile pattern would be expressed at the neural level as an inefficient recruitment of prefrontal regions normally involved in cognitive control.

Our findings could have a potential impact on research on neurocognitive markers of depression and are encouraging for a psychotherapeutic approach promoting cognitive flexibility, such as novel cognitive behavioral therapies integrating mindfulness practices. Indeed, mindfulness meditation has been shown to produce structural and functional changes in the lateral PFC and in the ACC (Chiesa and Serretti, 2010; Tang et al., 2012), and to improve autobiographical specificity in formerly depressed patients (Williams et al., 2000) and in healthy subjects (Heeren et al., 2009). Moreover, in the latter study improved AM was correlated with enhanced executive functions.

In conclusion, we showed in healthy young participants, that the degree of crystallized negative self-representation mimics the cognitive profile reported in depression concerning executive functions and AM, and that this pattern could be mediated by an inefficient recruitment of prefrontal structures involved in cognitive control of emotional response.

\section{ACKNOWLEDGMENTS}

The present study was supported by the National Hospital Clinical Research Program (PHRC NEMAUVI) allotted to Thierry Gallarda and Pascale Piolino, the Institut Universitaire de France (postdoc funding for Marco Sperduti and Sandrine Kalenzaga) and the Ministry of Higher Education and Research of France (Ph.D. funding of Pénélope Martinelli). We thank all volunteers for their participation in this study and the clinical and neuroimaging staff of the Center of Psychiatry and Neuroscience at Sainte Anne Hospital, especially Marion Delhommeau and Adèle Anssens. We would like greatly to thank Angela Carpenter and Todd Lubart for the language corrections of the manuscript. 


\section{REFERENCES}

Addis, D. R., Roberts, R. P., and Schacter, D. L. (2011). Age-related neural changes in autobiographical remembering and imagining. Neuropsychologia 49, 3656-3669.

Addis, D. R., and Tippett, L. J. (2004). Memory of myself: autobiographical memory and identity in Alzheimer's disease. Memory 12, 56-74.

Addis, D. R., Wong, A. T., and Schacter, D. L. (2008). Age-related changes in the episodic simulation of future events. Psychol. Sci. 19, 33-41.

Airaksinen, E., Larsson, M., Lundberg, I., and Forsell, Y. (2004). Cognitive functions in depressive disorders: evidence from a population-based study. Psychol. Med. 34, 83-91.

Austin, M. P., Mitchell, P., and Goodwin, G. M. (2001). Cognitive deficits in depression: possible implications for functional neuropathology. Br. J. Psychiatry 178, 200-206.

Baddeley, A. D., and Wilson, B. (1986). "Amnesia, autobiographical memory and confabulation," in Autobiographical Memory, ed. D. C. Rubin (Cambridge: Cambridge University Press), 225-252.

Badre, D., and Wagner, A. D. (2007). Left ventrolateral prefrontal cortex and the cognitive control of memory. Neuropsychologia 45, 2883-2901.

Barrett, L. F., Tugade, M. M., and Engle, R. W. (2004). Individual differences in working memory capacity and dual process theories of the mind. Psychol. Bull. 130, 553-573.

Beats, B., Sahakian, B., and Levy, R. (1996). Cognitive performance in tests sensitive to frontal lobe dysfunction in the elderly depressed. Psychol. Med. 26, 591-603.

Beblo, T., Baumann, B., Bogerts, B., Wallesch, C. W., and Herrmann, M. (1999). Neuropsychological correlates of major depression: a short term follow-up. Cogn. Neuropsychiatry 4, 333-341.

Beck, A. T. (1967). Depression: Clinical, Experimental, and Theoretical Aspects. New York: Hoeber.

Beck, A. T. (1976). Cognitive Therapy and the Emotional Disorders. New York: Penguin Books.

Beck, A. T. (2008). The evolution of the cognitive model of depression and its neurobiological correlates. Am. J. Psychiatry 165, 969-977.

Beck, A. T., Rush, A. J., Shaw, B. F., and Emery, G. (1979). Cognitive Therapy of Depression. New York: Guilford.

Beck, A. T., Steer, R. A., and Garbin, M. G. J. (1988). Psychometric properties of the Beck Depression Inventory twenty-five years of evaluation. Clin. Psychol. Rev. 8, 77-100.

Beckmann, M., Johansen-Berg, H., and Rushworth, M. F. (2009). Connectivity-based parcellation of human cingulate cortex and its relation to functional specialization. $J$. Neurosci. 29, 1175-1190.

Beevers, C. G., Clasen, P., Stice, E., and Schnyer, D. (2010). Depression symptoms and cognitive control of emotion cues: a functional magnetic resonance imaging study. Neuroscience 167, 97-103.

Biringer, E., Lundervold, A., Stordal, K., Mykletun, A., Egeland, J., Bottlender, R., et al. (2005). Executive function improvement upon remission of recurrent unipolar depression. Eur. Arch. Psychiatry Clin. Neurosci. 255, 373-380.

Bouvard, M., and Cottraux, J. (1996). Protocoles et échelles d'évaluation en psychiatrie et en psychologie. Paris: Masson.

Brett, M., Anton, J. L., Valbregue, R., and Poline, J. B. (2002). 8th International Conference on Functional Mapping of the Human Brain, June 2-6, Sendai. Available at: CD-ROM in NeuroImage. 16. Region of interest analysis using an SPM toolbox [abstract].

Brewin, C. R., Reynolds, M., and Tata, P. (1999). Autobiographical memory processes and the course of depression. J. Abnorm. Psychol. 108, 511-517.

Brittlebank, A. D., Scott, J., Williams, J. M. G., and Ferrier, I. N. (1993). Autobiographical memory in depression: state or trait marker? Br. J. Psychiatry 162, 118-121.

Brody, A. L., Saxena, S., Silverman, D. H., Alborzian, S., Fairbanks, L. A., Phelps, M. E., et al. (1999). Brain metabolic changes in major depressive disorder from pre- to posttreatment with paroxetine. Psych. Res. 91, 127-139.

Bryant, R. A., Sutherland, K., and Guthrie, R. M. (2007). Impaired specific autobiographical memory as a risk factor for posttraumatic stress after trauma. J. Abnorm. Psychol. 116, 837-841.

Buckner, R. L., Andrews-Hanna, J. R., and Schacter, D. L. (2008). The brain's default network: anatomy, function, and relevance to disease. Ann. N. Y. Acad. Sci. 1124, 1-38.

Bush, G., Luu, P., and Posner, M. I. (2000). Cognitive and emotional influences in anterior cingulate cortex. Trends Cogn. Sci. (Regul. Ed.) 4, 215-222.

Bush, G., Whalen, P. J., Rosen, B. R., Jenike, M. A., McInerney, S. C., and
Rauch, S. L. (1998). The counting Stroop: an interference task specialized for functional neuroimaging - validation study with functional MRI. Hum. Brain Mapp. 6, 270-282.

Cardebat, D., Doyon, B., Puel, M., Goulet, P., and Joanette, Y. (1990). Formal and semantic lexical evocation in normal subjects. Performance and dynamics of production as a function of sex, age and educational level. Acta Neurol. Belg. 90, 207-217.

Carver, C. S. (1988). Generalization, adverse events, and development of depressive symptoms. J. Pers. 66, 607-619.

Cavanna, A. E., and Trimble, M. R. (2006). The precuneus: a review of its functional anatomy and behavioural correlates. Brain 129, 564-583.

Chiesa, A., and Serretti, A. A. (2010). Systematic review of neurobiological and clinical features of mindfulness meditations. Psychol. Med. 40, 1239-1252.

Conway, M. A. (2001). Sensoryperceptual episodic memory and its context: autobiographical memory. Philos. Trans. R. Soc. Lond. B Biol. Sci. 356, 1375-1384.

Conway, M. A. (2005). Memory and the self. J. Mem. Lang. 53, 594-628.

Conway, M. A., and Fthenaki, A. (2000). "Disruption and loss of autobiographical memory," in Handbook of Neuropsychology, 2nd Edn, Vol. 2, eds F. Boller and J. Grafman (Amsterdam: Elsevier), 281-312.

Conway, M. A., and Pleydell-Pearce, C. W. (2000). The construction of autobiographical memories in the selfmemory system. Psychol. Rev. 107, 261-288.

Coste, C., Agar, N., Petit Four, A. L., Quinette, P., Guillery, B., Azouvi, P., et al. (2011). Relationship between executive fonctions and short-term feature binding in retrograde autobiographical memory in severe traumatic brain injury. Cortex 47, 771-786.

Dalgleish, T., Williams, J. M. G., Golden, A. M. J., Perkins, N., Barrett, L. F., Barnard, P. J., et al. (2007). Reduced specificity of autobiographical memory and depression: the role of executive processes. J. Exp. Psychol. Gen. 136, 23-42.

D’Argembeau, A., Jedidi, H., Balteau, E., Bahri, M., Phillips, C., and Salmon, E. (2012). Valuing one's self: medial prefrontal involvement in epistemic and emotive investments in selfviews. Cereb. Cortex 22, 659-667.
De Lissnyder, E., Koster, E. H. W., and De Raedt, R. (in press). Emotional interference in working memory is related to rumination. Cogn. Ther. Res.

Debeer, E., Raes, F., Mark, J., Williams, G., and Hermans, D. (2011). Context-dependent activation of reduced autobiographical memory specificity as an avoidant coping style. Emotion 11, 1500-1506.

Dent, J., and Teasdale, J. D. (1988). Negative cognition and the persistence of depression. J. Abnorm. Psychol. 97, 29-34.

Dichter, G. S., Felder, J. N., and Smoski, M. J. (2009). Affective context interferes with cognitive control in unipolar depression: an fMRI investigation. J. Affect. Disord. 14, 131-142.

Donaldson, D. I., Petersen, S. E., Ollinger, J. M., and Buckner, R. L. (2001). Dissociating state and item components of recognition memory using fMRI. Neuroimage 13, 129-142.

Drevets, W. C., and Price, J. L. (2005). "Neuroimaging and neuropathological studies of mood disorders," in Biology of Depression: From Novel Insights to Therapeutic Strategies, ed. J. W. M. Licinio (Weinheim: WileyVCH Verlag GmbH \& Co.,).

Duval, C., Eustache, F., and Piolino, P. (2007). Multidimensional self, autobiographical memory and aging. Psychol. Neuropsychiatr. Vieil. 5, 179-192.

Ellis, H. C., and Ashbrook, P. W. (1988). "Resource allocation model of the effects of depressed mood states on memory," in Affect, Cognition, and Social Behaviour, ed. J. Forgas (Toronto, ON: Hogrefe), 25-43.

Etkin, A., Egner, T., Peraza, D. M., Kandel, E. R., and Hirsch, J. (2006). Resolving emotional conflict: a role for the rostral anterior cingulate cortex in modulating activity in the amygdala. Neuron 51, 871-882.

Evraire, L. E., and Dozois, D. J. A. (2011). An integrative model of excessive reassurance seeking and negative feedback seeking in the development and maintenance of depression. Clin. Psychol. Rev. 31, 1291-1303.

Fitts, W., and Warren, W. (1996). Tennessee Self-Concept Scale Manual (Second Edition). Los Angeles: Western Psychological Services.

Fivush, R., and Nelson, K. (2004). Culture and language in the emergence of autobiographical memory. Psychol. Sci. 15, 573-577.

Fletcher, P. C., Shallice, T., Frith, C. D., Frackowiak, R. S., and Dolan, 
R. J. (1996). Brain activity during memory retrieval. The influence of imagery and semantic cueing. Brain 119, 1587-1596.

Foland-Ross, L. C., Hamilton, J. P., Joormann, J., Berman, M. G., Jonides, J., and Gotlib, I. H. (2013). The neural basis of difficulties disengaging from negative irrelevant material in major depression. Psychol. Sci. 24, 334-344.

Gardiner, J. M. (2001). Episodic memory and autonoetic consciousness: a first-person approach. Philos. Trans. R. Soc. Lond. B Biol. Sci. 356, 1351-1361.

George, M. S. E. C., Ketter, T. A., Parekh, P. I., Rosinsky, N., Ring, H., Pazzeglia, P. J., et al. (1997). Blunted left cingulate activation in mood disorder subjects during a response interference task (the Stroop). J. Neuropsychiatry Clin. Neurosci. 9, 55-63.

Gibbs, B. R., and Rude, S. S. (2004). Overgeneral autobiographical memory as depression vulnerability. Cogn. Ther. Res. 28, 511-526.

Goeleven, E., De Raedt, R., Baert, S., and Koster, E. H. W. (2006). Deficient inhibition of emotional information in depression. J. Affect. Disord. 93, 149-157.

Gohier, B., Ferracci, L., Surguladze, S. A., Lawrence, E., El-Hage, W., Kefi, M. Z., et al. (2009). Cognitive inhibition and working memory in unipolar depression. J. Affect. Disord. 116, 100-105.

Gotlib, I. H., and Hamilton, J. P. (2008). Neuroimaging and depression: current status and unresolved issues. Curr. Dir. Psychol. Sci. 17, 159-163.

Gotlib, I. H., and Joormann, J. (2010). Cognition and depression: current status and future directions. Annu. Rev. Clin. Psychol. 6, 285-312.

Greicius, M. D., Flores, B. H., Menon, V., Glover, G. H., Solvason, H. B., Kenna, H., et al. (2007). Resting-state functional connectivity in major depression: abnormally increased contributions from subgenual cingulate cortex and thalamus. Biol. Psychiatry 62, 429-437.

Hamilton, J. P., and Gotlib, I. H. (2008). Neural substrates of increased memory sensitivity for negative stimuli in major depression. Biol. Psychiatry 63, 1155-1162.

Hammen, C. (2005). Stress and depression. Annu. Rev. Clin. Psychol. 1, 293-319.

Harrison, C. L., and Fowler, D. (2004). Negative symptoms, trauma, and autobiographical memory: an investigation of individuals recovering from psychosis. J. Nerv. Ment. Dis. 192, 745-753.
Hasher, L., and Zacks, R. T. (1979). Automatic and effortful processes in memory. J. Exp. Psychol. Gen. 108, 356-388.

Hasler, G., Drevets, W. C., Manji, H. K., and Charney, D. S. (2004). Discovering endophenotypes for major depression. Neuropsychopharmacology 29, 1765-1781.

Hedden, T., and Gabrieli, J. D. (2010). Shared and selective neural correlates of inhibition, facilitation, and shifting processes during executive control. Neuroimage 51, 421-431.

Heeren, A., Van Broeck, N., and Philippot, P. (2009). The effects of mindfulness on executive processes and autobiographical memory specificity. Behav. Res. Ther. 47, 403-409.

Henson, R. N., Hornberger, M., and Rugg, M. D. (2005). Further dissociating the processes involved in recognition memory: an FMRI study. J. Cogn. Neurosci. 17, 1058-1073.

Hermans, D., Vandromme, H., Debeer, E., Raes, F., Demyttenaere, K., Brunfaut, E., et al. (2008). Overgeneral autobiographical memory predicts diagnostic status in depression. Behav. Res. Ther. 46, 668-677.

Hertel, P. T., and Rude, S. (1991). Depressive deficits in memory: focusing attention improves subsequent recall. J. Exp. Psychol. Gen. 120, 301-309.

Ingram, R. E., and Siegle, G. J. (2002). "Methodological issues in depression research: not your father's oldsmobile," in Handbook of Depression, 3rd Edn, eds I. Gotlib and C. Hammen (New York: Guilford Press).

Ingram, R. E., Steidtmann, D. K., and Bistricky, S. L. (2008). "Information processing: attention and memory," in Risk Factors in Depression, eds K. S. Dobson and D. J. A. Dozois (San Diego, CA: Academic Press), 145-169.

Iqbal, Z., Birchwood, M., Hemsley, D., Jackson, C., and Morris, E. (2004). Autobiographical memory and postpsychotic depression in first episode psychosis. Br. J. Clin. Psychol. 43, 97-104.

James, W. (1890). Principles of Psychology. Chicago: University of Chicago Press.

Joiner, T. E., Jr. (2000). Depression's vicious scree: self-propagating and erosive processes in depression chronicity. Clin. Psychol. Sci. Pr. 7, 203-218.

Joormann, J. (2004). Attentional bias in dysphoria: the role of inhibitory processes. Cogn. Emot. 18, 125-147.
Klein, S. B., and Gangi, C. E. (2010). The multiplicity of self: neuropsychological evidence and its implications for the self as a construct in psychological research. Ann. N. Y. Acad. Sci. 1191, 1-15.

Konishi, S., Wheeler, M. E., Donaldson, D. I., and Buckner, R. L. (2000). Neural correlates of episodic retrieval success. Neuroimage 12 , 276-286.

Kringelbach, M. L., and Rolls, E. T. (2004). The functional neuroanatomy of the human orbitofrontal cortex: evidence from neuroimaging and neuropsychology. Prog. Neurobiol. 72, 341-372.

Kuyken, W., and Dalgleish, T. (1995). Autobiographical memory and depression. Br. J. Clin. Psychol. 33, 89-92.

Legrand, D., and Ruby, P. (2009). What is self-specific? Theoretical investigation and critical review of neuroimaging results. Psychol. Rev. 116, 252-282.

Lemogne, C., Piolino, P., Friszer, S., Claret, A., Girault, N., Jouvent, R. et al. (2006). Episodic autobiographical memory in depression: specificity, autonoetic consciousness and self-perspective. Conscious. Cogn. 15, 258-268.

Levine, B., Cabeza, R., McIntosh, A. R., Black, S. E., Grady, C. L., and Stuss, D. T. (2002). Functional reorganisation of memory after traumatic brain injury: a study with $\mathrm{H}(2)(15) 0$ positron emission tomography. $J$. Neurol. Neurosurg. Psychiatr. 73, 173-181.

Linville, P. (1996). "Attention inhibition: does it underlie ruminative thought?," in Ruminative Thoughts. Advances in Social Cognition, Vol. 9, ed. R. S. Wyer Jr. (Mahwah, NJ: Lawrence Erlbaum), 121-133.

Lo, B. C. Y., and Allen, N. B. (2011). Affective bias in internal attention shifting among depressed youth. Psychiatry Res. 187, 125-129.

Mackinger, H. F., Loschin, G. G., and Leibetseder, M. M. (2000). Prediction of postnatal affective changes by autobiographical memories. Eur. Psychol. 5, 52-61.

MacQueen, G. M., Tipper, S. P., Young L. T., Joffe, R. T., and Levitt, A. J. (2000). Impaired distractor inhibition on a selective attention task in unmedicated, depressed subjects. Psychol. Med. 30, 557-564.

Markela-Lerenc, J., Kaiser, S., Fiedler, P., Weisbrod, M., and Mundt, C. (2006). Stroop performance in depressive patients: a preliminary report. J. Affect. Disord. 94, 261-267.
Martinelli, P., Anssens, A., Sperduti, M., and Piolino, P. (2013). The influence of normal aging and Alzheimer's disease in autobiographical memory highly related to the self. Neuropsychology 27, 69-78.

Martinelli, P., Sperduti, M., and Piolino, P. (2012). Neural substrates of the self-memory system: new insights from a meta-analysis. Hum. Brain Mapp. doi:10.1002/hbm.22008

Matuszewski, V., Piolino, P., de la Sayette, V., Lalevée, C., Pèlerin, A., Dupuy, B., et al. (2006). Retrieval mechanisms for autobiographical memories: insights from the frontal variant of frontotemporal dementia. Neuropsychologia 44, 2386-2397.

Mayberg, H. S., Liotti, M., Brannan, S. K., McGinnis, S., Mahurin, R. K., Jerabek, P. A., et al. (1999). Reciprocal limbic-cortical function and negative mood: converging PET findings in depression and normal sadness. Am. J. Psychiatr. 156, 675-682.

McDermott, K. B., Jones, T. C., Petersen, S. E., Lageman, S. K., and Roediger, H. L. (2000). Retrieval success is accompanied by enhanced activation in anterior prefrontal cortex during recognition memory: an event-related fMRI study. J. Cogn. Neurosci. 12, 965-976.

McNally, R. J., Litz, B. T., Prassas, A., Shin, L. N., and Weathers, F. (1994). Emotional priming and autobiographical memory in posttraumatic stress disorder. Cogn. Emot. 8, 351-368.

Meiran, N., Diamond, G. M., Todor, D., and Nemtes, B. (2010). Cognitive rigidity in unipolar depression and obsessive compulsive disorder: examination of task switching, Stroop, working memory updating and post-conflict adaptation. Psychiatry Res. 185, 149-156.

Miller, E. K. (2000). The prefrontal cortex and cognitive control. Nat. Rev. Neurosci. 1, 59-65.

Miller, E. K., Freedman, D. J., and Wallis, J. D. (2002). The prefrontal cortex: categories, concepts and cognition. Philos. Trans. R. Soc. Lond. B Biol. Sci. 357, 1123-1136.

Mirabel-Sarron, C., Vera, L., and Samuel-Lajeunesse, B. (2001). Estime de soi et dépression. Ann. Méd-Psychol. 159, 144-148.

Miyake, A., Friedman, N. P., Emerson, M. J., Witzki, A. H., and Howerter A. (2000). The unity and diversity of executive functions and their contribution to complex "frontal lobe" tasks: a latent variable analysis. $\operatorname{Cog} n$. Psychol. 41, 49-100. 
Mongrain, M. (1990). "Motivational aspects of vulnerable personality styles," in Presentation at the Graduate Student Colloquium of the D.O. Hebb lecture series (Montreal: McGill).

Morley, T. E., and Moran, G. (2011). The origins of cognitive vulnerability in early childhood: mechanisms linking early attachment to later depression. Clin. Psychol. Rev. 31, 1071-1082.

Morris, N., and Jones, D. M. (1990). Habituation to irrelevant speech: effects on a visual short-term memory task. Percept. Psychophys. 47, 291-297.

Murrough, J. W., Iacoviello, B., Neumeister, A., Charney, D. S., and Iosifescu, D. V. (2011). Cognitive dysfunction in depression: neurocircuitry and new therapeutic strategies. Neurobiol. Learn. Mem. 96, 553-563.

Naismith, S. L., Hickie, I. B., Turner, K., Little, C. L., Winter, V., Ward, P. B., et al. (2003). Neuropsychological performance in patients with depression is associated with clinical, etiological and genetic risk factors. J. Clin. Exp. Neuropsychol. 25, 866-877.

Naylor, E., and Clare, L. (2008). Awareness of memory functioning, autobiographical memory and identity in early-stage dementia. Neuropsychol. Rehabil. 18, 590-606.

Neu, P., Kiesslinger, U., Schlattmann, P., and Reischies, F. (2001). Timerelated cognitive deficiency in four different types of depression. Psychiatry Res. 103, 237-247.

Niendam, T. A., Laird, A. R., Ray, K. L., Dean, Y. M., Glahn, D. C., and Carter, C. S. (2012). Metaanalytic evidence for a superordinate cognitive control network subserving diverse executive functions. Cogn. Affect. Behav. Neurosci. 12, 241-268.

Nixon, E., Liddle, P. F., Nixon, N. L., and Liotti, M. (2012). On the interaction between sad mood and cognitive control: the effect of induced sadness on electrophysiological modulations underlying Stroop conflict processing. Int. J. Psychophysiol. doi:10.1016/j.ijpsycho.2012.11.014

Nolen-Hoeksema, S., and Watkins, E. R. (2011). A heuristic for developing transdiagnostic models of psychopathology: explaining multifinality and divergent trajectories. Perspect. Psychol. Sci. 6, 589-609.

Northoff, G., and Bermpohl, F. (2004). Cortical midline structures and the self. Trends Cogn. Sci. 8, 102-107.
O’Brien, E. J., Bartoletti, M., and Leitzel, J. D. (2006). "Self-esteem, psychopathology, and psychotherapy," in Self-esteem Issues and Answers: A Sourcebook of Current Perspectives, ed. M. H. Kernis (New York: Psychology Press), 306-315.

Ochsner, K. N., and Gross, J. J. (2005). The cognitive control of emotion. Trends Cogn. Sci. 9, 242-249.

Ochsner, K. N., Ray, R. D., Cooper, J. C., Robertson, E. R., Chopra, S., Gabrieli, J. D., et al. (2004). For better or for worse: neural systems supporting the cognitive downand up-regulation of negative emotion. NeuroImage 23, 483-499.

Oldfield, R. C. (1971). The assessment and analysis of handedness: the Edinburgh inventory. Neuropsychologia 9, 97-113.

Peeters, F., Wessel, L., Merckelbach, H., and Boon-Vermeeren, M. (2002). Autobiographical memory specificity and the course of major depressive disorder. Compr. Psychiatry 43, 344-350.

Petrides, M. (1995). Functional organization of the human frontal cortex for mnemonic processing. Evidence from neuroimaging studies. Ann. N. Y. Acad. Sci. 769, 85-96.

Petrides, M. (2002). The midventrolateral prefrontal cortex and active mnemonic retrieval. Neurobiol. Learn. Mem. 78, 528-538.

Petrides, M. (2005). Lateral prefrontal cortex: architectonic and functional organization. Philos. Trans. R. Soc. Lond. B Biol. Sci. 360, 781-795.

Picard, L., Mayor-Dubois, C., Meader, F., Kalenzaga, S., Duval, C., Abram, M., et al. (in press). Functional independence within the self-memory system: new insights from two cases of developmental amnesia. Cortex.

Piolino, P., Chételat, G., Matuszewski, V., Landeau, B., De La Sayette, V., Eustache, F., et al. (2007a). In search of autobiographical memories: a PET study in frontotemporal dementia. Neuropsychologia 45, 2730-2743.

Piolino, P., Desgranges, B., Manning, L., North, P., Jokic, F., and Eustache, F. (2007b). Autobiographical memory, the sense of recollection and executive functions after severe closed head injury. Cortex 2, 176-195.

Piolino, P., Coste, C., Martinelli, P., Macé, A. M., Quinette, P., Guillery-Gerard, B., et al. (2010). Reduced specificity of autobiographical memory and aging: do the executive and feature binding functions of working memory have a role? Neuropsychologia 48, 429-440.
Piolino, P., Desgranges, B., and Eustache, F. (2009). Episodic autobiographical memories over the course of time: cognitive, neuropsychological and neuroimaging findings. Neuropsychologia 47, 2314-2329.

Quinette, P., Guillery, B., Desgranges, B., de la Sayette, V., Viader, F., and Eustache, F. (2003). Working memory and executive functions in transient global amnesia. Brain 126, 1917-1934.

Raes, F., Hermans, D., Williams, J. M. G., and Eelen, P. (2006). Reduced autobiographical memory specificity and affect regulation. Cogn. Emot. 20, 402-429.

Raes, F., Hermans, D., Williams, J. M. G., and Eelen, P. (2007). A sentence completion procedure as an alternative to the autobiographical memory test for assessing overgeneral memory in non-clinical populations. Memory 15, 495-507.

Raes, F., Verstraeten, K., Bijttebier, P., Vasey, M. W., and Dalgleish, T. (2010). Inhibitory control mediates the relationship between depressed mood and overgeneral memory recall in children. J. Clin. Child Adolesc. Psychol. 39, 276-281.

Ray, R. D., Ochsner, K. N., Cooper, J. C., Robertson, E. R., Gabrieli, J. D. E., and Gross, J. J. (2005). Individual differences in trait rumination and the neural systems supporting cognitive reappraisal. Cogn. Affect. Behav. Neurosci. 5, 156-168.

Reischies, F., and Neu, P. (2000). Comorbidity of mild cognitive disorder and depression - a neuropsychological analysis. Eur. Arch. Psychiatry Clin. Neurosci. 4, 186-193.

Reitan, R. (1958). Validity of the Trail Making Test as an indication of organic brain damage. Percept. Mot. Skills 8, 271-276.

Riutort, M., Cuervo, C., Danion, J. M. Peretti, C. S., and Salame, P. (2003). Reduced levels of specific autobiographical memories in schizophrenia. Psychiatry Res. 117, 35-45.

Rogers, T. B., Kuiper, N. A., and Kirker, W. S. (1977). Self-reference and the encoding of personal information. $J$. Pers. Soc. Psychol. 35, 677-688.

Ros, L., Latorre, J. M., and Serrano, J. P. (2010). Working memory capacity and overgeneral autobiographical memory in young and older adults. Neuropsychol. Dev. Cogn. B Aging Neuropsychol. Cogn. 17, 89-107.

Rosen, V. M., and Engle, R. W. (1997). The role of working memory capacity in retrieval. J. Exp. Psychol. Gen. 126, 211-227.
Sajonz, B., Kahnt, T., Margulies, D. S., Park, S. Q., Wittmann, A., and Stoy, M. (2010). Delineating selfreferential processing from episodic memory retrieval: common and dissociable networks. Neuroimage 50, 1606-1617.

Segal, Z. V., and Ingram, R. E. (1994). Priming and construct activation in test of cognitive vulnerability to unipolar depression. Clin. Psychol. Rev. 14, 663-695.

Shafritz, K. M., Collins, S. H., and Blumberg, H. P. (2006). The interaction of emotional and cognitive neural systems in emotionally guided response inhibition. Neuroimage 31, 468-475.

Sheehan, D. V., Lecrubier, Y., Sheehan, K. H., Amorim, P., Janavs, J., Weiller, E., et al. (1998). The Mini-International Neuropsychiatric Interview (M.I.N.I.): the development and validation of a structured diagnostic psychiatric interview for DSM-IV and ICD-10. J. Clin. Psychiatry 59, 22-33.

Siegle, G. J., Thompson, W., Carter, C. S., Steinhauer, S. R., and Thase, M. E. (2007). Increased amygdala and decreased dorsolateral prefrontal BOLD responses in unipolar depression: related and independent features. Biol. Psychiatry 61, 198-209.

Sowislo, J. F., and Orth, U. (2012). Does low self-esteem predict depression and anxiety? a meta-analysis of longitudinal studies. Psychol. Bull. 139, 213-240.

Stroop, J. R. (1935). Studies of interference in serial verbal reactions. J. Exp. Psychol. 18, 643-662.

Symons, C. S., and Johnson, B. T. (1997). The self-reference effect in memory: a meta-analysis. Psychol. Bull. 121, 371-394.

Tang, Y. Y., Lu, Q., Fan, M., Yang, Y., and Posner, M. I. (2012). Mechanisms of white matter changes induced by meditation. Proc. Natl. Acad. Sci. U.S.A. 109, 10570-10574.

Tulving, E. (2002). Episodic memory: from mind to brain. Annu. Rev. Psychol. 53, 1-25.

Van Minnen, A., Wessel, I., Verhaak, C., and Smeenk, J. (2005). The relationship between autobiographical memory specificity and depressed mood following a stressful life event: a prospective study. Br. J. Clin. Psychol. 44, 405-415.

Viard, A., Lebreton, K., Chételat, G., Desgranges, B., Landeau, B., Young, A., et al. (2010). Patterns of hippocampal - neocortical interactions in the retrieval of episodic autobiographical memories across the entire 
life-span of aged adults. Hippocampus 20, 153-165.

Wager, T. D., Davidson, M. L., Hughes, B. L., Lindquist, M. A., and Ochsner, K. N. (2008). Prefrontalsubcortical pathways mediating successful emotion regulation. Neuron 59, 1037-1050.

Wang, L., LaBar, K. S., Smoski, M., Rosenthal, M. Z., Dolcos, F., Lynch, T. R., et al. (2008). Prefrontal mechanisms for executive control over emotional distraction are altered in major depression. Psychiatry Res. 163, 143-155.

Watkins, E., and Teasdale, J. D. (2001). Rumination and overgeneral memory in depression: effects of selffocus and analytic thinking. $J$. Abnorm. Psychol. 110, 353-357.

Watson, L. A., Bertsen, D., Kuyken, W., and Watkins, E. R. (2013). Involuntary and voluntary autobiographical memory specificity as a function of depression. J. Behav. Ther. Exp. Psychiatry 44, 7-13.
Wechsler, D. (2000). Wechsler Adults Intelligence Scale, 3rd Edn, Paris: Les Editions du Centre de Psychologie Appliquée.

Wessel, I., Meeren, M., Peeters, F., Arntz, A., and Merckelbach, H. (2001). Correlates of autobiographical memory specificity: the role of depression, anxiety and childhood trauma. Behav. Res. Ther. 39, 409-421.

Whalen, P. J., Bush, G., McNally, R. J.,Wilhelm, S., McInerney, S. C., Jenike, M. A., et al. (1998). The emotional counting Stroop paradigm: a functional magnetic resonance imaging probe of the anterior cingulate affective division. Biol. Psychiatry 44, 1219-1228.

Williams, J. M., Teasdale, J. D., Segal, Z. V., and Soulsby, J. (2000). Mindfulness-based cognitive therapy reduces overgeneral autobiographical memory in formerly depressed patients. J. Abnorm. Psychol. 109, 150-155.

Williams, J. M. G., Barnhofer, T., Crane, C., Hermans, D., Raes, F., Watkins,
E., et al. (2007). Autobiographical memory specificity and emotional disorder. Psychol. Bull. 113, 122-148. Williams, J. M. G., and Dritschel, B. (1992). "Categoric and extended autobiographical memories," in Theoretical Perspectives on Autobiographical Memory, eds M. A. Conway, D. C. Rubin, H. Spinnler, and W. A. Wagenaar (Dordrecht: Kluwer Academic), 391-410.

Winthorpe, C., and Rabbitt, P. A. (1988). "Working memory capacity, IQ, age, and the ability to recount autobiographical events," in Practical Aspects of Memory: Current Research and Issues II, eds M. M. Gruneberg, P. E. Morris, and R. N. Sykes (Chichester: Wiley), 175-179.

Conflict of Interest Statement: The authors declare that the research was conducted in the absence of any commercial or financial relationships that could be construed as a potential conflict of interest.
Received: 12 March 2013; paper pending published: 27 March 2013; accepted: 22 April 2013; published online: 21 May 2013.

Citation: Sperduti $M$, Martinelli $P$, Kalenzaga $S$, Devauchelle $A-D$, Lion $S$, Malherbe C, Gallarda T, Amado I, Krebs M-O, Oppenheim $C$ and Piolino P (2013) Don't be too strict with yourself! Rigid negative selfrepresentation in healthy subjects mimics the neurocognitive profile of depression for autobiographical memory. Front. Behav. Neurosci. 7:41. doi: 10.3389/fnbeh.2013.00041

Copyright (c) 2013 Sperduti, Martinelli, Kalenzaga, Devauchelle, Lion, Malherbe, Gallarda, Amado, Krebs, Oppenheim and Piolino. This is an openaccess article distributed under the terms of the Creative Commons Attribution License, which permits use, distribution and reproduction in other forums, provided the original authors and source are credited and subject to any copyright notices concerning any third-party graphics etc. 


\section{APPENDIX}

Table A1 | Excerpt of the Taste and Interest Questionnaire (TIO).

\begin{tabular}{|c|c|c|c|}
\hline Activities & Pertinence & Importance & Frequency \\
\hline \multicolumn{4}{|l|}{ TRAVELS } \\
\hline France & 1 & 7 & $\mathrm{~F}$ \\
\hline Abroad & 1 & 8 & $\mathrm{~F}$ \\
\hline Asia & 1 & 9 & $\mathbf{R}$ \\
\hline North America & 0 & & \\
\hline South America & 0 & & \\
\hline Africa & 1 & 9 & $\mathbf{R}$ \\
\hline North Europe & 1 & 6 & $\mathrm{~F}$ \\
\hline South Europe & 1 & 8 & $\mathrm{~F}$ \\
\hline East Europe & 0 & & \\
\hline \multicolumn{4}{|c|}{ PHYSICAL ACTIVITIES } \\
\hline Sports (general) & 1 & 8 & $\mathrm{~F}$ \\
\hline Team sports & 0 & & \\
\hline Water sports & 0 & & \\
\hline Tennis & 1 & 4 & $\mathrm{R}$ \\
\hline Golf & 1 & 8 & $\mathbf{R}$ \\
\hline Athletics & 0 & & \\
\hline Relaxation & 1 & 9 & $\mathbf{R}$ \\
\hline Equitation & 1 & 10 & $\mathrm{~F}$ \\
\hline Dance & 0 & & \\
\hline
\end{tabular}

Activities were selected as a cue for autobiographical recall only if they were pertinent, important (>5), and rare. Items marked in bold are examples of activities selected according the above mentioned criteria. 